\title{
Article
}

\section{Unmanned Aircraft Systems in Remote Sensing and Scientific Research: Classification and Considerations of Use}

\author{
Adam C. Watts ${ }^{1}{ }^{*}$, Vincent G. Ambrosia ${ }^{2}$ and Everett A. Hinkley ${ }^{3}$ \\ 1 School of Natural Resources and Environment, University of Florida, P.O. Box 110410, \\ Gainesville, FL 32611, USA \\ 2 California State University, Monterey Bay/NASA-Ames Research Center, P.O. Box 1, MS 245-4, \\ Bld. 245, Moffett Field, CA 94035, USA; E-Mail: vincent.g.ambrosia@ nasa.gov \\ 3 USDA Forest Service, 1601 N. Kent Street, Suite 500, Arlington, VA 22209, USA; \\ E-Mail: ehinkley@fs.fed.us
}

* Author to whom correspondence should be addressed; E-Mail: acwatts@ufl.edu; Tel.: +1-352-318-2471; Fax: +1-352-846-0841.

Received: 7 April 2012; in revised form: 1 June 2012 / Accepted: 4 June 2012 /

Published: 8 June 2012

\begin{abstract}
Unmanned Aircraft Systems (UAS) have evolved rapidly over the past decade driven primarily by military uses, and have begun finding application among civilian users for earth sensing reconnaissance and scientific data collection purposes. Among UAS, promising characteristics are long flight duration, improved mission safety, flight repeatability due to improving autopilots, and reduced operational costs when compared to manned aircraft. The potential advantages of an unmanned platform, however, depend on many factors, such as aircraft, sensor types, mission objectives, and the current UAS regulatory requirements for operations of the particular platform. The regulations concerning UAS operation are still in the early development stages and currently present significant barriers to entry for scientific users. In this article we describe a variety of platforms, as well as sensor capabilities, and identify advantages of each as relevant to the demands of users in the scientific research sector. We also briefly discuss the current state of regulations affecting UAS operations, with the purpose of informing the scientific community about this developing technology whose potential for revolutionizing natural science observations is similar to those transformations that GIS and GPS brought to the community two decades ago.
\end{abstract}

Keywords: Unmanned Aircraft System (UAS); UAV; drone; aerial survey 


\section{Introduction}

Unmanned Aircraft Systems (UAS), also referred to as drones, unmanned aerial vehicles (UAVs), and remotely piloted aircraft (RPA), have a lengthy military pedigree that reflects their long-recognized potential in supporting warfare efforts. Although their highly publicized missions may convey the impression that UAS are a recent technological innovation, the use of unmanned flight pre-dates human-piloted flight. Aerial bombardment of Venice in 1849 was undertaken (albeit ineffectively) by unmanned hot-air balloons [1], and similar balloons were used in the American Civil War [2,3]. Military reconnaissance missions with unmanned aerial platforms occurred as soon as suitable photographic apparatus were developed; Corporal William Eddy of the US Army used remotely-triggered cameras aboard kites in the 1898 Spanish-American War [4]. Throughout the history of military aviation, development of unmanned aircraft has continued apace, with developments in human-piloted flight often inspiring (or being inspired by) new unmanned aircraft technology.

The early focus on UAS supporting the so-called "three Ds" (i.e., dull, dirty, or dangerous missions in which human pilot operations would be at a disadvantage or at high risk) highlighted the natural niche for UAS. Improvements in reconnaissance and guidance capabilities during the Cold War spurred interest among the scientific community in utilizing UAS for science missions in which pilotless aircraft provided similar advantages and risk mitigation. The US National Aeronautics and Space Administration (NASA) developed unmanned aircraft for high-altitude atmospheric sampling during the "Mini-Sniffer" program of the 1970s-1980s, but with limited success, and little follow-on activities. NASA's Environmental Research Aircraft and Sensor Technology (ERAST) program in the 1990s marked the first major steps towards developing the protocols and capabilities for employment of UAS supporting scientific research. However, the military pedigree of most unmanned aircraft systems yielded a dichotomy in the nature of most systems: UAS capable of carrying powerful and accurate sensors tended to be large and very expensive, while small platforms lacked payloads to deliver precision data. The latter group of UAS was better suited to budgets or logistical demands of many research organizations, but had been designed for situational awareness as opposed to survey-grade data delivery. One of the major findings of the ERAST program and subsequent UAS science community workshops was the need for sensor miniaturization to allow the use of smaller-class (and affordable) UAS platforms.

Inspired by NASA efforts and improvements in miniaturization, the late 1990s saw numerous efforts among smaller organizations to develop or modify UAS tailored to their own research needs. Applications as diverse as atmospheric sampling [5] and rangeland vegetation monitoring [6] employed hobbyist-grade radio-control (RC) models, with varying degrees of success. The "age of the 'do-it-yourself' (DIY) drone" evolved quickly as researchers found low-cost solutions based on modified radio-controlled models to be less than adequate for many needs. Additionally, the recognition that UAS offer tremendous potential for many areas of scientific research and monitoring has spurred significant demand in the public sector for systems that combine the sensor or sampling quality typically found in large aircraft with the portability and cost advantages provided by smaller systems. The user community, relying on RC aircraft to support data gathering also found a niche in the FAA regulations that allow such platform utility within certain flight constraints and conditions. 
Smaller-class UAS were not considered as RC-type aircraft by the FAA and therefore were excluded from those more lenient use allowances.

Today, a large array of options is available to UAS users, and those without long-standing involvement in this field may face a steep learning curve, which can be a barrier to entry. Additionally, an increasing number of regulations affect the use of UAS in most countries, and can appear both confusing and discouraging for the newcomer. As participants in the UAS community for several years, our intentions are to introduce the technology described in this Special Issue to a readership who will see its increasing prevalence in civilian sectors as a readily-available and precise tool for remote sensing data collection and sampling. Specifically, our objectives are (1) to describe various classes and categories of UAS and considerations for their use; (2) to describe the general types and capabilities of sensor packages available for UAS, and their relative suitability for representative scientific applications; and (3) to introduce important principles of government regulation of UAS, with specific examples from the USA and Europe.

\section{UAS Platform Types and Characteristics}

Unmanned aircraft systems consist of the aircraft component, sensor payloads, and a ground control station. The latter, operated by one or more people in addition to a dedicated human "pilot" (supplemented in some cases by an additional "spotter" to ensure safety), varies widely in its configuration depending on the platform and mission. Dedicated control systems may be devoted to large UAVs, and mounted aboard vehicles or in trailers to enable close proximity to UAVs limited by range or communication capabilities. The smallest categories of UAVs often are accompanied by ground-control stations consisting of laptop computers and other components small enough to be carried easily with the aircraft in small vehicles, aboard boats, or in backpacks.

\subsection{Classification of UAS Platforms}

Classification of UAS platforms for civil scientific uses has generally followed existing military descriptions of the platforms based upon characteristics such as size, flight endurance, and capabilities (Figure 1). The generally accepted class nomenclature in the civilian realm is as follows:

MAV (Micro (or Miniature) or NAV (Nano) Air Vehicles): are so called because of their size, which typically enables military versions of these aircraft to be transported within individual soldiers' backpacks. These aircraft tend to operate at very low altitudes $(<330 \mathrm{~m})$, with size limitations on battery capacity leading to short flight times in the vicinity of $c a$. 5-30 min.

VTOL (Vertical Take-Off \& Landing): These aircraft require no takeoff or landing run, and are therefore typically chosen in situations where limitations of terrain require this specialized capability. Aircraft of this type operate at varying altitudes depending on their mission profile, but predominantly fly at low altitudes. High power requirements for hovering flight limit the flight durations for VTOLs, except in the largest sizes where increased lifting capabilities accommodate large fuel capacity.

LASE (Low Altitude, Short-Endurance): systems, also known as sUAS, small unmanned aircraft systems, also obviate the need for runways with aircraft optimized for easy field deployment/recovery and transport. The aircraft component of these systems typically weighs $c a .2-5 \mathrm{~kg}$, 
with wingspans $<3 \mathrm{~m}$ to enable launching from miniature catapult systems, or by hand. Compromises between weight and capability tend to reduce endurance and communication ranges to $1-2 \mathrm{~h}$ and within a few $\mathrm{km}$ of ground stations.

LASE Close: This category describes small UAS whose aircraft do require runways, but whose larger size and weight confer increased capabilities. These systems operate at up to ca. 1,500 m altitude and may remain aloft for multiple hours, although these limits have been substantially exceeded by specially-modified "record-breaker" aircraft.

LALE (Low Altitude, Long Endurance): Typically at the upper end of the "sUAS" weight designation by the United States Federal Aviation Administration (FAA; see below), these UAS may carry payloads of several $\mathrm{kg}$ at altitudes of a few thousand meters for extended periods.

MALE (Medium Altitude, Long Endurance): aircraft are typically much larger than low-altitude classes of UAVs, operating at altitudes up to $c a .9,000 \mathrm{~m}$ on flights hundreds of $\mathrm{km}$ from their ground stations lasting many hours.

HALE (High Altitude, Long Endurance): These are the largest and most complex of the UAS, with aircraft larger than many general-aviation manned aircraft. These UAVs may fly at altitudes of 20,000 $\mathrm{m}$ or more on missions that extend thousands of $\mathrm{km}$. Some HALE aircraft have flight durations over $30 \mathrm{~h}$, and have set records for altitude and flight duration.

Figure 1. Image courtesy of US Department of Homeland Security [7].

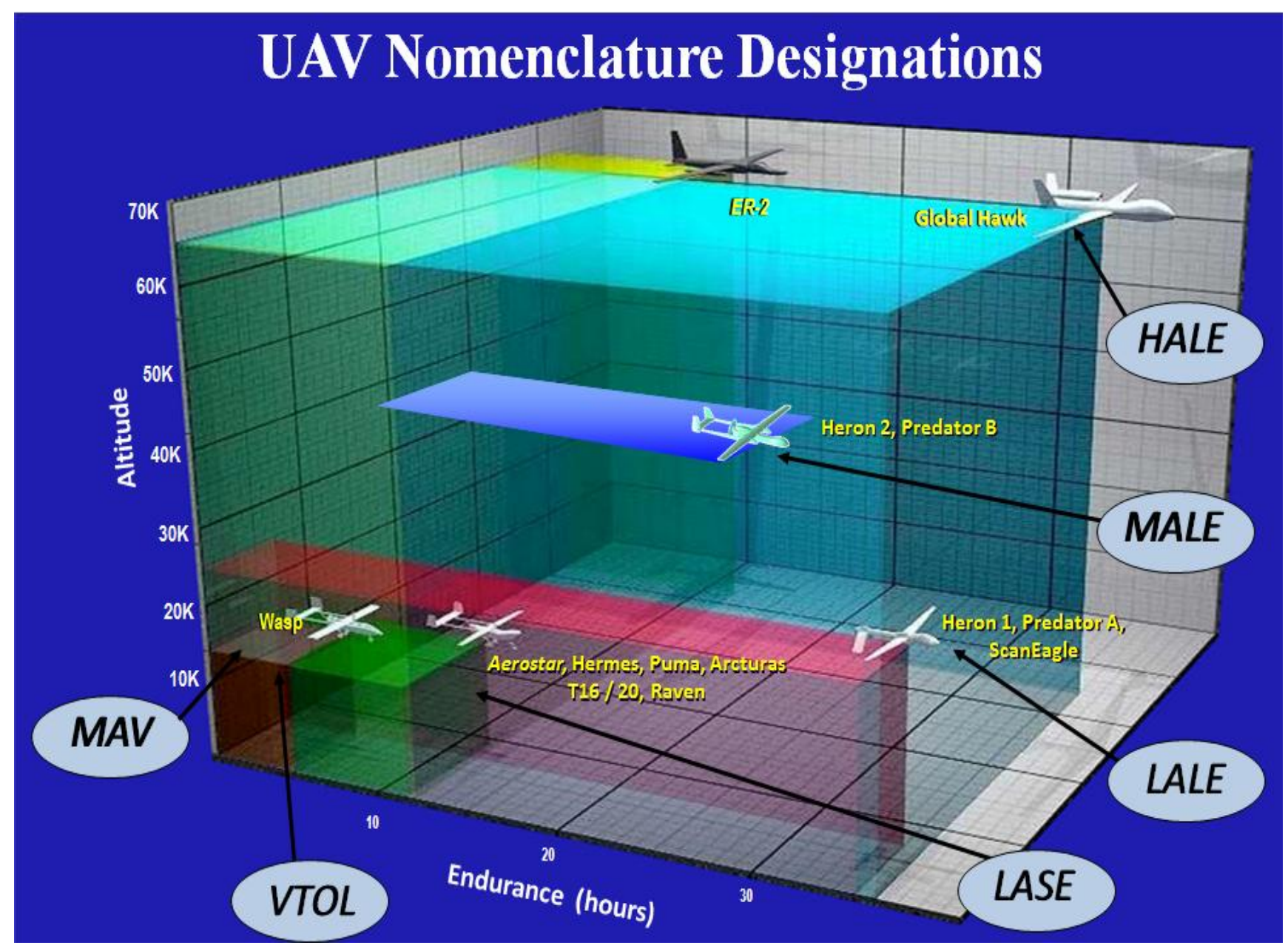


For the purposes of simplicity we will describe some characteristics of the various size platforms for supporting civilian remote sensing and scientific research applications from the former identified categories of UAS (MAV, LALE, LASE, MALE, HALE, and VTOL).

\subsection{Characteristics and Examples of UAS Categories}

\subsubsection{MAV/NAV UAS}

Very small UAS or Micro-UAVs (MAVs) and Nano UAVs (NAVs) are designed as short mission profile surveillance platforms, allowing unobtrusive observation capabilities in confined spaces or hostile environments in military applications. The major MAV development thrusts started in the mid-late 1990s with major development support from the US Department of Defense. Most of these systems developed by industry, such as the Lockheed Sanders "MicroSTAR", the AeroVironment "MicroBat" and "Black Widow", and the Lutronix "Kolibri", are designed with small color video system payloads.

Nano UAVs (NAVs) in development, such as the AeroVironment "Nano Hummingbird" are extremely small, low-altitude, short-duration UAS platforms designed to enhance situational awareness in areas where they may go unobserved. The AV Nano Hummingbird is the size of a small bird (e.g., weight of $19 \mathrm{~g}$ and wingspan of $16 \mathrm{~cm}$ ) and can climb and descend vertically, fly in all horizontal directions, is equipped with a small video camera, and has a flight endurance of $\sim 8 \mathrm{~min}$ (Figure 2 ).

Figure 2. Courtesy AeroVironment, Inc. (http://www.avinc.com).

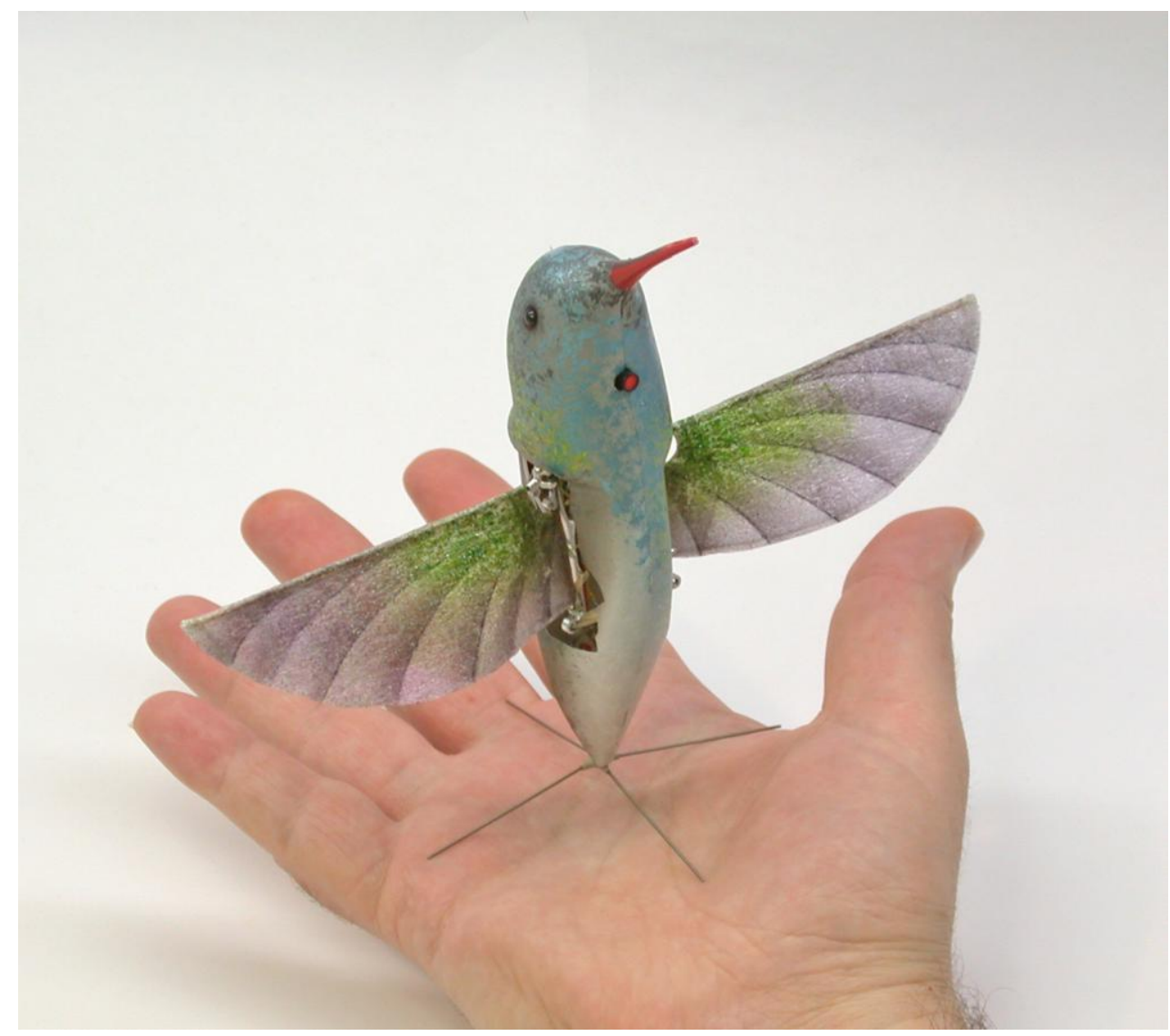


Development of MAVs and NAVs for the commercial market is in its infancy, and no examples of their uses yet exist. These UAS assets may prove to be effective or inexpensive systems to gather information for law enforcement and may have some utility for wildlife inventories and other remote sensing civilian applications.

\subsubsection{VTOL UAS}

Most VTOL UAV history dates to the early 1960s (with a single exception of the creation of the Rolls-Royce Thrust Measuring Rig in the 1950s), and work progressed slowly through the 1970s and 1980s as technological limitations hampered the ability of engineers to realize the design goals for these vehicles. As these problems were overcome, major VTOL UAV developments occurred in the 1990s and through to the present. Figure 3 depicts dates of first flights or operational use of VTOL UAS, and their increased rate of development since the late 1990s (data for 2012 are estimates).

Figure 3. Unmanned VTOL commercial platform systems developed (horizontal axis) by year between 1960-2012. Data for 2012 are estimates at the time of writing.

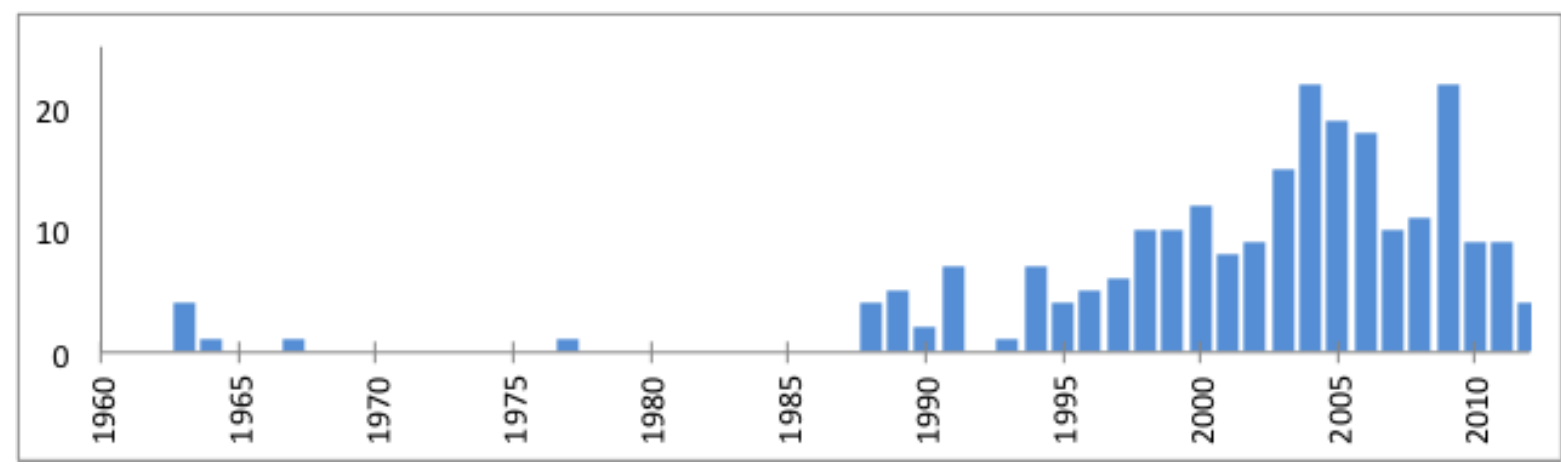

The advantages of VTOL UAS are the portability of the platforms for remote area operations without the necessity for runway complexes. More of the current VTOL platforms are small, with most operating with electric motors from rechargeable batteries limiting flight durations to less than one hour. They have limited sensor payload capabilities but as miniaturization of sensors occurs, the platforms are proving more valuable for use in quick analysis situations. Examples of the utility of VTOL UAS platforms are to support law enforcement operations, where a low-altitude, hovering capability with image data capture is useful for ascertaining an incident scene. Scientific research applications requiring loitering capability over a fixed survey plot of relatively small size (e.g., agricultural field) are another area in which this category of UAV has significant potential. These platforms have also been demonstrated (in practice missions) in support of structure damage analysis and rescue operations in a complex urban structure environment (narrow streets, buildings, etc.). With ease of maneuverability, VTOL can more readily negotiate an urban landscape at low altitude than can fixed-wing assets.

For most VTOL UAS, Line-of-sight (LOS) operations are the common pilot control method. Most VTOL UAS operations for "quick-look" analysis (over the hill, around the building, etc.) can be readily accomplished with a one- or two-person crew, making these platforms cost-effective for short-duration observational needs The Draganflyer X6 (Figure 4) is one example of such a system, 
with its $1 \mathrm{~kg}$ tri-rotor platform capable of lofting payloads of $500 \mathrm{~g}$ to altitudes of 2,400 $\mathrm{m}$ flights of up to 20 minute-flights. The Aeryon Scout (Figure 5), of similar size $(80 \mathrm{~cm} \times 30 \mathrm{~cm}$ ), carries a $300 \mathrm{~g}$ payload to heights of $330 \mathrm{~m}$ within an operational range of $3 \mathrm{~km}$ from its ground control station. Larger VTOL UAS systems are in development primarily to support military lift and transport operations (such as moving equipment in hostile, remote environments), but their wider application to supporting science and civilian utility has not been established yet.

Figure 4. Draganflyer X6 VTOL UAS. Image courtesy Draganfly Innovations, Inc.

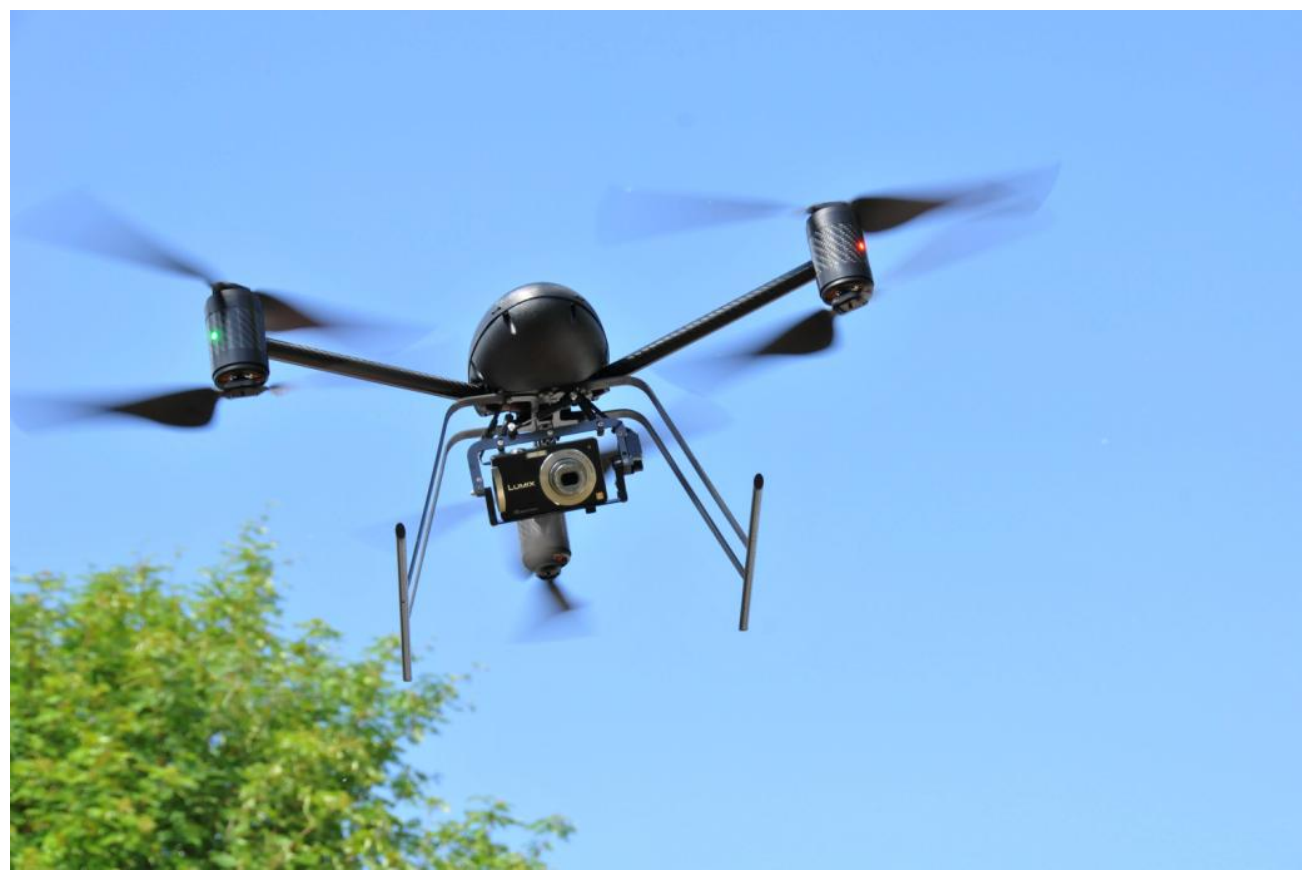

Figure 5. Aeryon Scout VTOL UAS. Image courtesy Aeryon Labs, Inc.

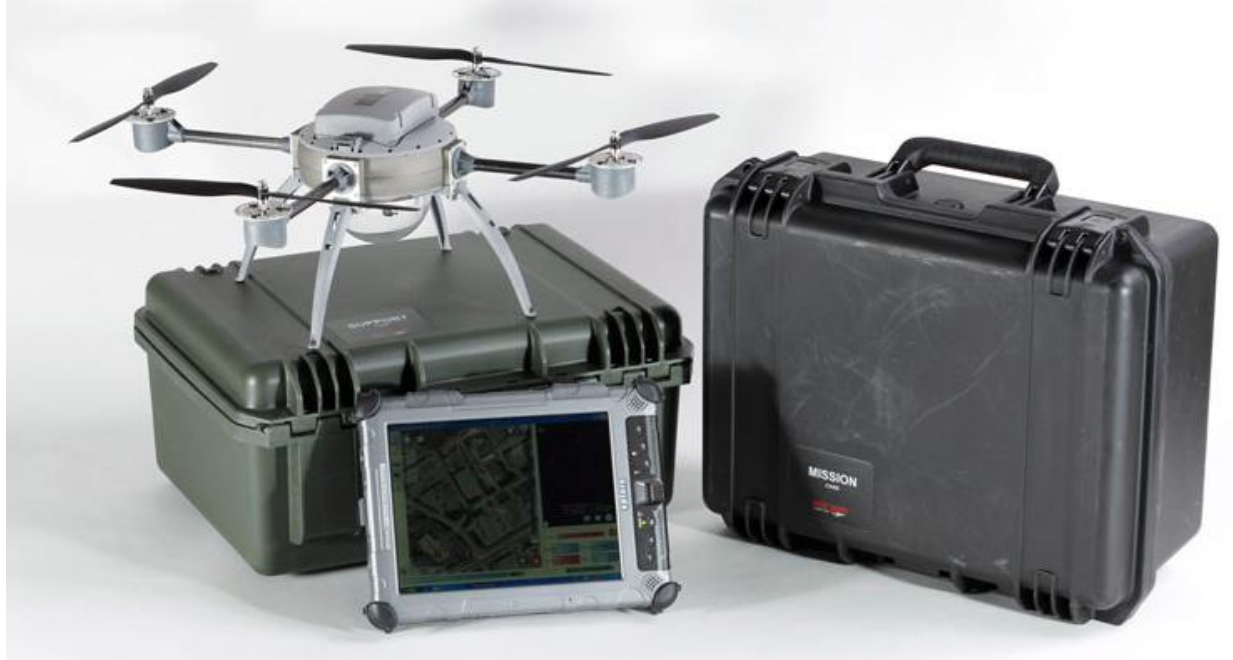

An example of a mid-sized, commercially used VTOL UAS is the Yamaha RMAX (Figure 6). The RMAX is a two cycle/two cylinder UAS helicopter with a $28 \mathrm{~kg}$ load capacity, $3.13 \mathrm{~m}$ main rotor diameter platform with remote control systems via a line-of-sight ground control station. It has been 
employed primarily for agricultural spraying operations in Japan, Australia and other locations. RMAX has the payload capacity and endurance to support remote sensing system operations, and has flown with various experimental remote sensing systems at NASA-Ames Research Center in a collaborative effort with the US Army under the NASA/Army Autonomous Rotorcraft Project (ARP) [8].

Figure 6. The Yamaha RMAX VTOL aircraft, shown with a pesticide/herbicide application sprayer payload used in precision agriculture. Image courtesy of Yamaha Motor Australia.

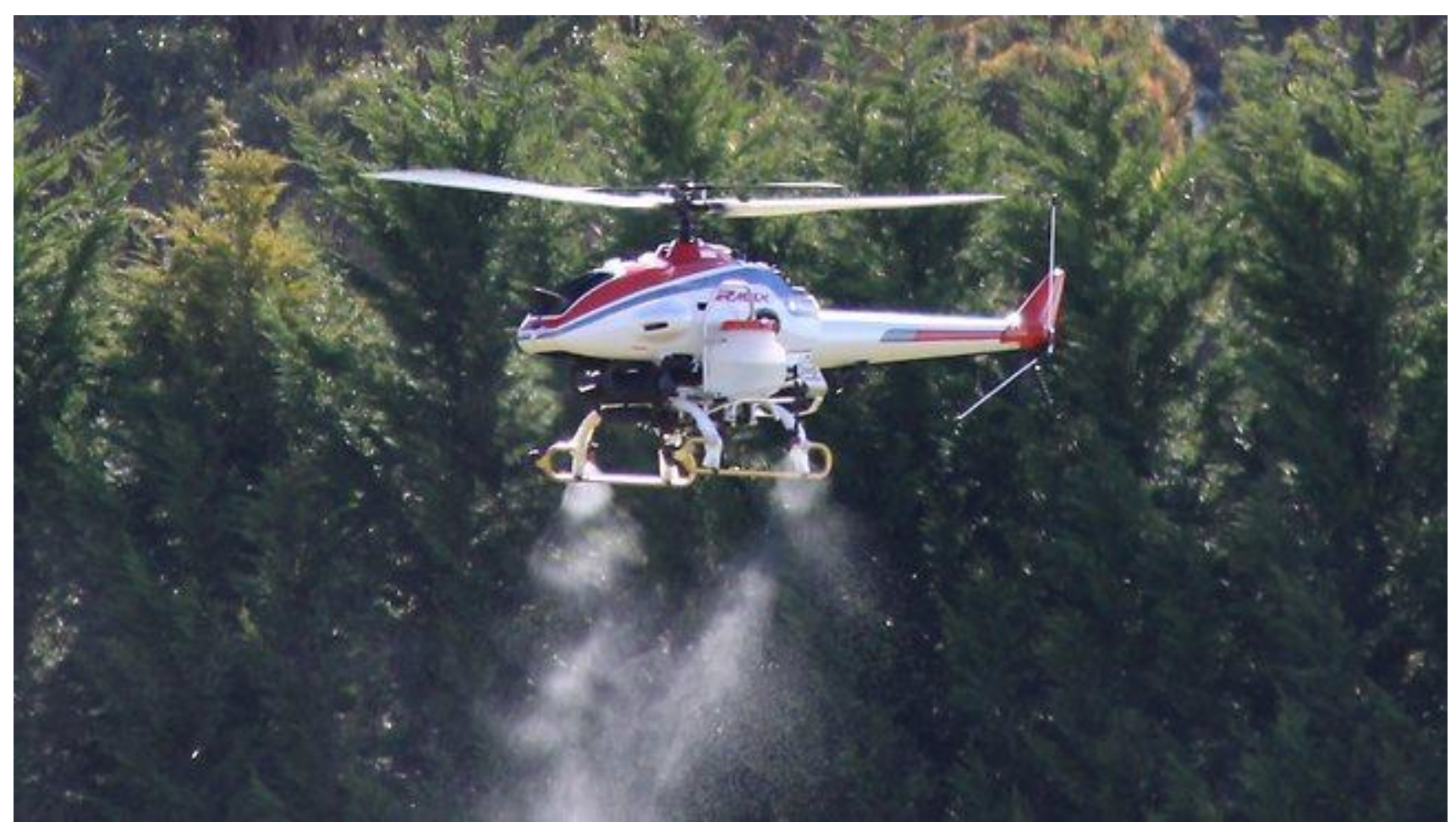

\subsubsection{LASE/LALE UAS}

Low-altitude, Short Endurance and Low-Altitude, Long Endurance UAS occur in an array of sizes and configurations, from back-packable, hand-launched platforms to catapult-launch platforms (Figure 7). Some of the more common, low-cost LASE/LALE platforms in use today are those that are lightweight and can be hand-launched, allowing versatile field condition operations in areas without solid surface runways [9]. The disadvantage of hand-launch platforms is their relative short-duration operational capabilities of $45 \mathrm{~min}-2 \mathrm{~h}$, and a reduced payload capacity.

The LALE/LASE UAS are relatively simple to operate, with flight controls similar to RC models and simplified ground-control stations that allow for small crews. Most of the remote sensing systems are small, simplified cameras or streaming video cameras in either daylight (color or B/W) or infrared (B/W) video provided of surface objects being imaged, although increased capabilities are enabling direct image georeferencing in some of these systems. 
Figure 7. LASE and LALE UAS on display at 2005 Naval Unmanned Aerial Vehicle Air Demo. Pictured are (front to back, left to right) RQ-11A Raven, Evolution, Dragon Eye, NASA FLIC, Arcturus T-15, Skylark, Tern, RQ-2B Pioneer, and Neptune. Image Courtesy US Department of Defense.

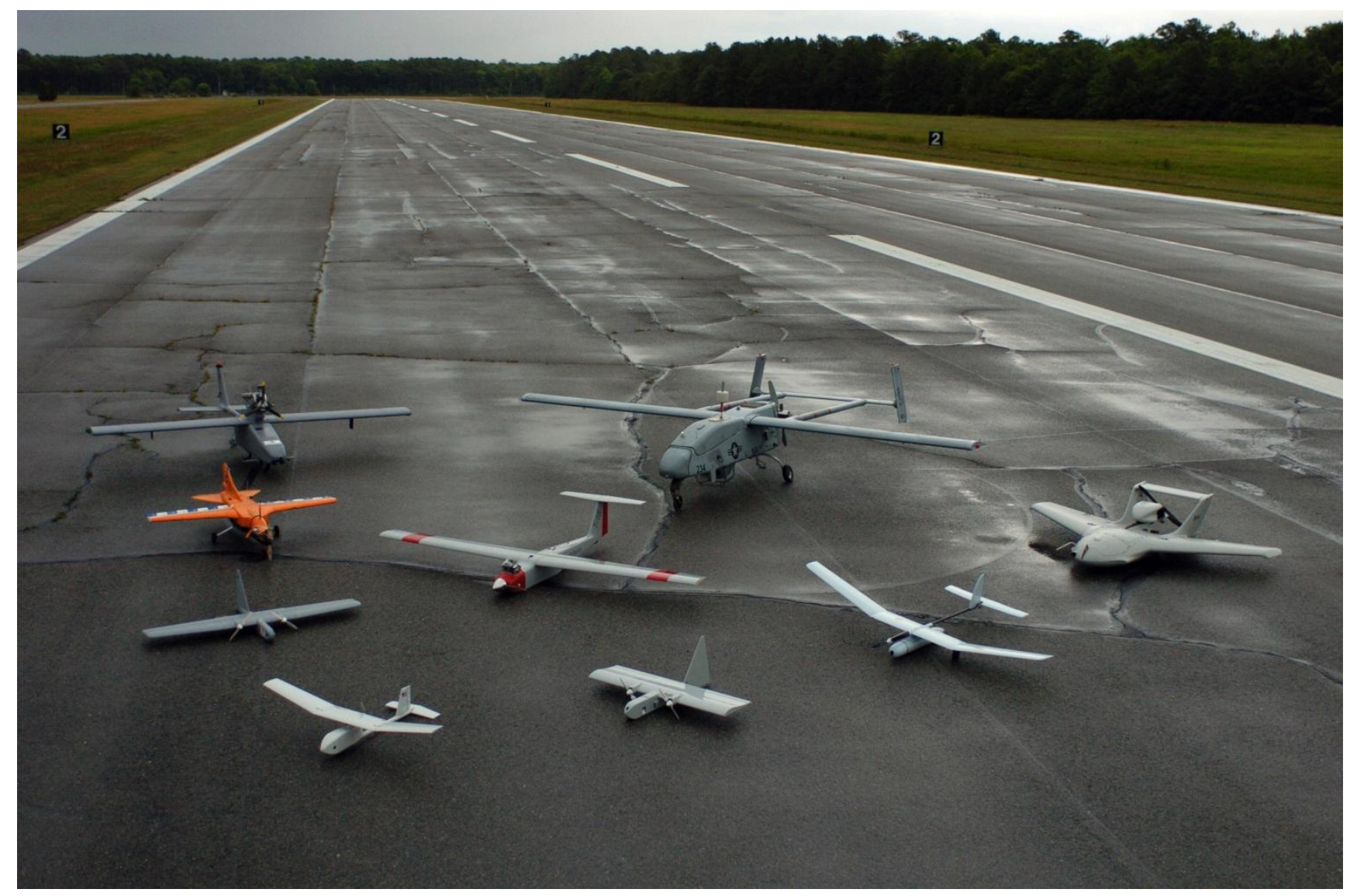

\subsubsection{MALE UAS}

Medium Altitude, Long-Endurance UAS platforms play a significant role in strategic operations in the defense community and are also seeing increased use within a few civil applications areas. An exemplary MALE platform in civilian use is the NASA Ikhana UAS, a Predator-B derivative platform operated in support of NASA's Science Mission Directorate, Earth Science Division (Figure 8). The Ikhana was delivered to NASA Dryden Flight Research Center (DFRC) at Edwards Air Force Base in early 2007. The name Ikhana, a Native American Choctaw word meaning intelligent, conscience or aware, was considered descriptive of research goals NASA had established for the aircraft and its related systems at the time [10]. The Ikhana's $20 \mathrm{~m}$ wingspan can loft payloads of nearly $200 \mathrm{~kg}$ internally, as well as external loads of $900 \mathrm{~kg}$. The aircraft is capable of reaching altitudes above $12,000 \mathrm{~m}$, but with limited endurance at that altitude. The aircraft performance characteristics are optimized at 5,500 $\mathrm{m}$ to 9,000 $\mathrm{m}$ feet altitude, where the aircraft is capable of $\sim 24$-hour mission endurance.

The Ikhana UAS supported remote sensing data collection during its first campaign flights from 2007-2009. During the Western States UAS Fire Imaging Missions, the aircraft flew over 20 missions in the western United States over 60 fires, testing and developing imaging capabilities for wildfire mensuration. The missions were supported by a partnership of NASA, the US Forest Service and 
CALFIRE with a focus to develop the sensor and data communications capabilities to provide near-real-time wildfire information from a long-endurance UAS flying throughout extensive regions of the western US [10-12]. The missions, over a period of three fire seasons, showcased the utility of UAS to support both scientific data collection and disaster monitoring capabilities. By employing the satellite communications system (command and control $(\mathrm{C} \& \mathrm{C})$ ) link on the Ikhana as a distribution mechanism for delivery of data from the Autonomous Modular Sensor (AMS) aboard the Ikhana, the team was able to deliver near-real-time, geo-rectified imagery to incident management teams within 10-15 min of acquisition. This allowed an improved understanding of fire conditions by the incident teams to allow maximization of firefighting resources. Table 1 lists wildfire imaging support missions flown by Ikhana (and its predecessor, Altair) during the 2006-2009 fire seasons. While successful in demonstrating the capabilities of UAS for wildfire mapping and surveillance, these efforts were suspended in subsequent years and their future status is uncertain.

Figure 8. NASA Ikhana. Image courtesy NASA.

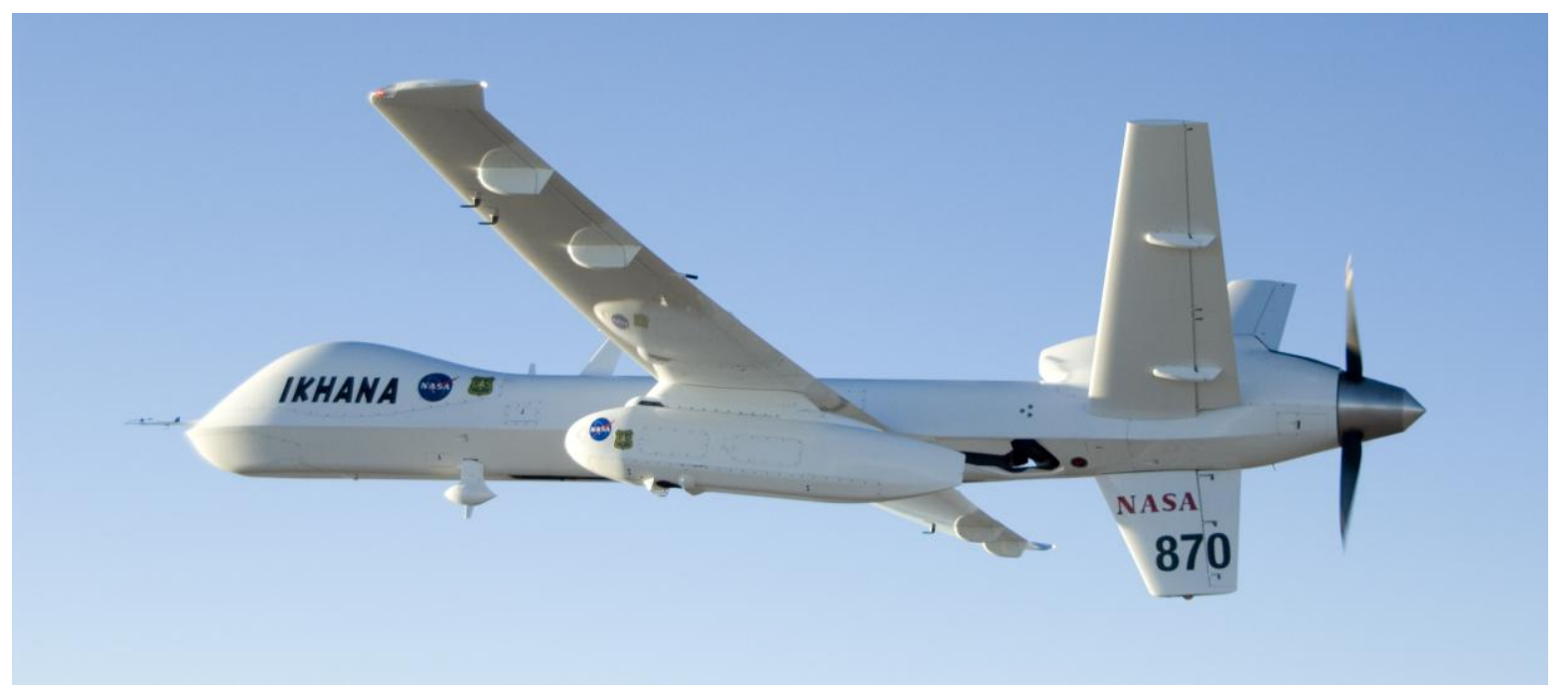

Table 1. Summary of Western (US) States Fire Mission (WSFM) flights, 2006-2009.

\begin{tabular}{|c|c|c|c|c|}
\hline Year & Aircraft & Flights & Hours & Fires Flown \\
\hline 2006 & Altair & 4 & 68 & Mono Lake Prescribed Fire, Esperanza Fire (CA) \\
\hline 2007 & Ikhana & 12 & 89 & $\begin{array}{l}\text { Zaca, Tar, Colby, Babcock, Jackrabbit, Butler, North, Fairmont, Grouse, } \\
\text { Lick, Bald, Moonlight, Zaca, SoCal Firestorm (CA); Trapper Ridge, Castle } \\
\text { Rock (ID); WH (MT); Columbine, Hardscrabble, Granite Creek (WY); GW, } \\
\text { Big Basin (OR); Domke Lake, South Omak (WA) }\end{array}$ \\
\hline 2008 & Ikhana & 4 & 21 & $\begin{array}{l}\text { Piute, Clover, Silver, North Mountain, American River, Cub Complex, } \\
\text { Canyon Complex, Basin, Gap, Camp, Cascatel, Hidden (CA) }\end{array}$ \\
\hline 2009 & Ikhana & 2 & 11 & Piute, Station Fire (CA; post-burn assessments) \\
\hline
\end{tabular}

CA: California; ID: Idaho; MT: Montana; WY: Wyoming; OR: Oregon; WA: Washington.

The Ikhana was also the first civilian UAS to receive a Certificate of Airworthiness (COA; see below) to operate in the National Airspace System (NAS) without any chase aircraft or observers. The platform was granted extensive coverage of the western US in order to support disaster imaging over wildfire events, and was given unprecedented FAA COA support during the Southern California 
October 2007 firestorms that caused extensive damage, evacuations of $\sim 500,000$ people, and considerable loss of life. During that mission period (over five days) the Ikhana was granted access to airspace over densely populated regions of southern California, an event never before allowed by the FAA. Ikhana flew at a constant altitude of FL230 (7,000 m), under constant control of a NASA pilot through some of the world's busiest airspace, supporting image data collection over 11 wildfires near San Diego and Los Angeles metropolitan areas. This mission series opened the door for greater UAS capabilities within the remote sensing data collection community and demonstrated the safe operations of larger UAS in support of regional assessments of environmental conditions.

The NASA Altus II UAS was a modified General Atomics Gnat-750 used as the platform for the Altus Cumulus Electrification Study (ACES), which investigated thunderstorms in Florida, USA, in 2002. ACES investigated the relationship between storm electrical activity and storm morphology, and validated satellite-based lightning measurements. ACES also demonstrated the utility and promise of UAV platforms for Earth science. The payload included sensors to characterize lightning activity and the electrical environment near thunderstorms, contributing electrical and optical observations unavailable from other sources. The Altus's endurance allowed flights near and over thunderstorms for long periods of time that allowed investigations to be conducted over entire storm life cycles [13].

The NASA Sensor Integrated Environmental Remote Research Aircraft (SIERRA) is a MALE-class, unmanned aircraft system (UAS) that can perform remote sensing and atmospheric sampling missions in isolated and often inaccessible regions (Figure 9). Designed by the US Naval Research Laboratory and developed at NASA's Ames Research Center, the $180 \mathrm{~kg}$ (gross takeoff weight) SIERRA can carry a $45 \mathrm{~kg}$ payload on flights lasting up to 10 hours, at a maximum altitude of $3,600 \mathrm{~m}$ and at airspeeds of $100 \mathrm{~km} / \mathrm{h}$.

Figure 9. The NASA SIERRA, shown flying near Svalbard, Norway, 2009. Image courtesy NASA.

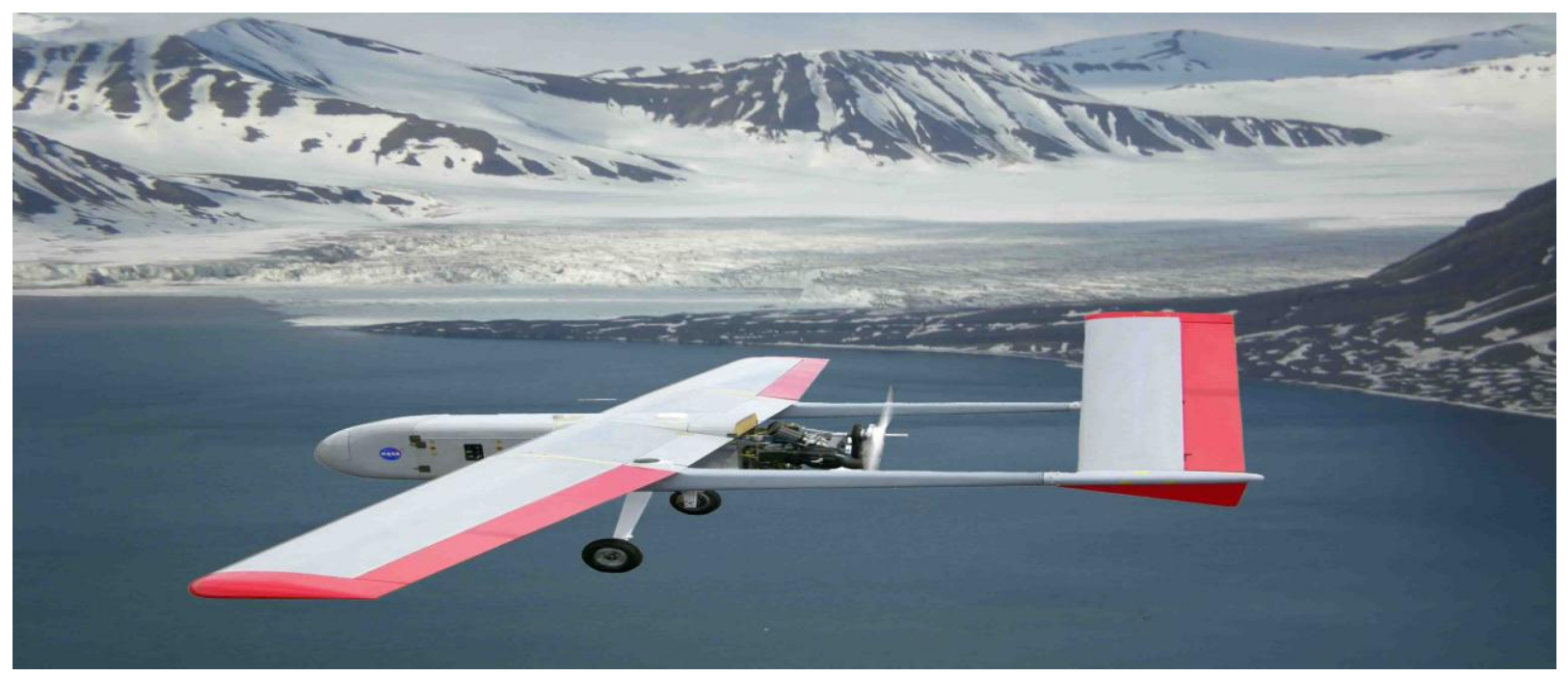

The SIERRA has supported several airborne science data collection campaigns, including the following missions:

- CASIE (2009): The Characterization of Arctic Sea Ice Experiment operated from Svalbard, Norway, above the Arctic Circle. The CASIE experiment focused on measurement of sea-ice 
roughness via remote sensing to try to detect basic changes in ice conditions such as thickness and ice age and other factors;

- RAM-GGM (2011): The Right-of Way Automated Monitoring-Greenhouse Gas Mission pilot study occurred in Railroad Valley, NV, USA, with the focus to test bed instruments for autonomously detecting and locating methane releases from petroleum production, extraction sites and distribution networks. The missions in June 2011 with a Cavity-Ring Flux Analyzer onboard the SIERRA aircraft were successful in mapping methane levels in the lower atmosphere above a variety of locales in Railroad Valley;

- Long-Term Earthquake Hazards and groundwater measurement UAS (SIERRA) campaign (2011-2013): The SIERRA platform is being used to characterize seismic hazard potential and map paths for groundwater flow using high resolution magnetic field data collections along faults and fractures in otherwise inaccessible terrain in the western US (Oregon and California).

- High Resolution Assessment of Carbon Dynamics in Seagrass and Coral Reef Biomes (2011-2013): This SIERRA UAS mission focuses on hyperspectral bio-optical observations to assess core physiological and biogeochemical variables in seagrass and shallow tropical coral habitats. The primary SIERRA mission areas are the areas around Cedar Key, FL, USA, and Buccal Reef, Tobago (Caribbean Sea).

The use of MALE platforms is appropriate when data collection is required at regional scales and at altitudes common to manned aircraft. The use of MALE platforms does prove logistically difficult for the Federal Aviation Administration (FAA) Certificate of Airworthiness (COA) process (see below), because the aircraft are operating in the typical flight altitude parameters of most civilian and commercial manned aircraft, posing a potential airspace hazard. Because of these issues, the most logical first steps in UAS operation in the National Airspace System (NAS) will be from smaller LALE and LASE UAS platforms.

\subsubsection{HALE UAS}

High Altitude, Long Endurance UAS platforms are a more recent introduction into the UAS world. Outside of the US Department of Defense, the major civilian components that have employed HALE UAS to support science have been NASA and the US National Oceanographic and Atmospheric Administration (NOAA). Their driving scientific objectives necessitate the use of HALE platforms to collect information at regional and global scales to allow assessments of climate variable impacts across broad regions of the globe and to support satellite observations at spatial and temporal scales, not achievable with less capable manned or unmanned platforms. Therefore, the platforms identified in this section are primarily those operated by NASA in collaboration with other agencies. These platforms have stepped beyond the experimental stage and are now, in some cases, employed operationally (e.g., Global Hawk) to support remote sensing collection and earth/atmospheric science investigations. Because of their operational uniqueness and capabilities, these platforms are prohibitively expensive for most users; they are therefore used to support large investigative science campaigns, rather than smaller, localized assessments where other categories of UAS or manned platforms prove more cost-effective. 
In the 1990s, a joint NASA-industry initiative (ERAST) to validate the capabilities of UAS to fly operational science missions was undertaken. One of the program goals was to develop UAS operational capabilities of $\sim 30,000 \mathrm{~m}$ feet altitude and $>24$-h duration. During the program efforts, the following milestones were achieved:

- Sustained flight above 16,700 m for four hours by the Altus UAS in 1999 after being equipped with a powerful turbocharger;

- An altitude of over 17,000 m achieved by the Perseus B in 1998, an unofficial record for a turbocharged single-engine, propeller-driven craft;

- An altitude of 24,460 m achieved by the Pathfinder-Plus in August 1998, a world record for both propeller-driven and solar-powered aircraft.

- An unofficial world-record altitude of 29,543 m achieved by the Helios Prototype in August, 2001, more than two miles higher than any non-rocket powered aircraft had ever flown.

- A follow-on NASA-supported endeavor, the UAV Science Demonstration Program (UAV-SDP) led to a successful crop, forest and coral reef imaging science demonstrations mission by the Pathfinder over the Hawaiian island of Kauai in 1997 (Figure 10).

Figure 10. The Pathfinder HALE UAS. Image Courtesy NASA.

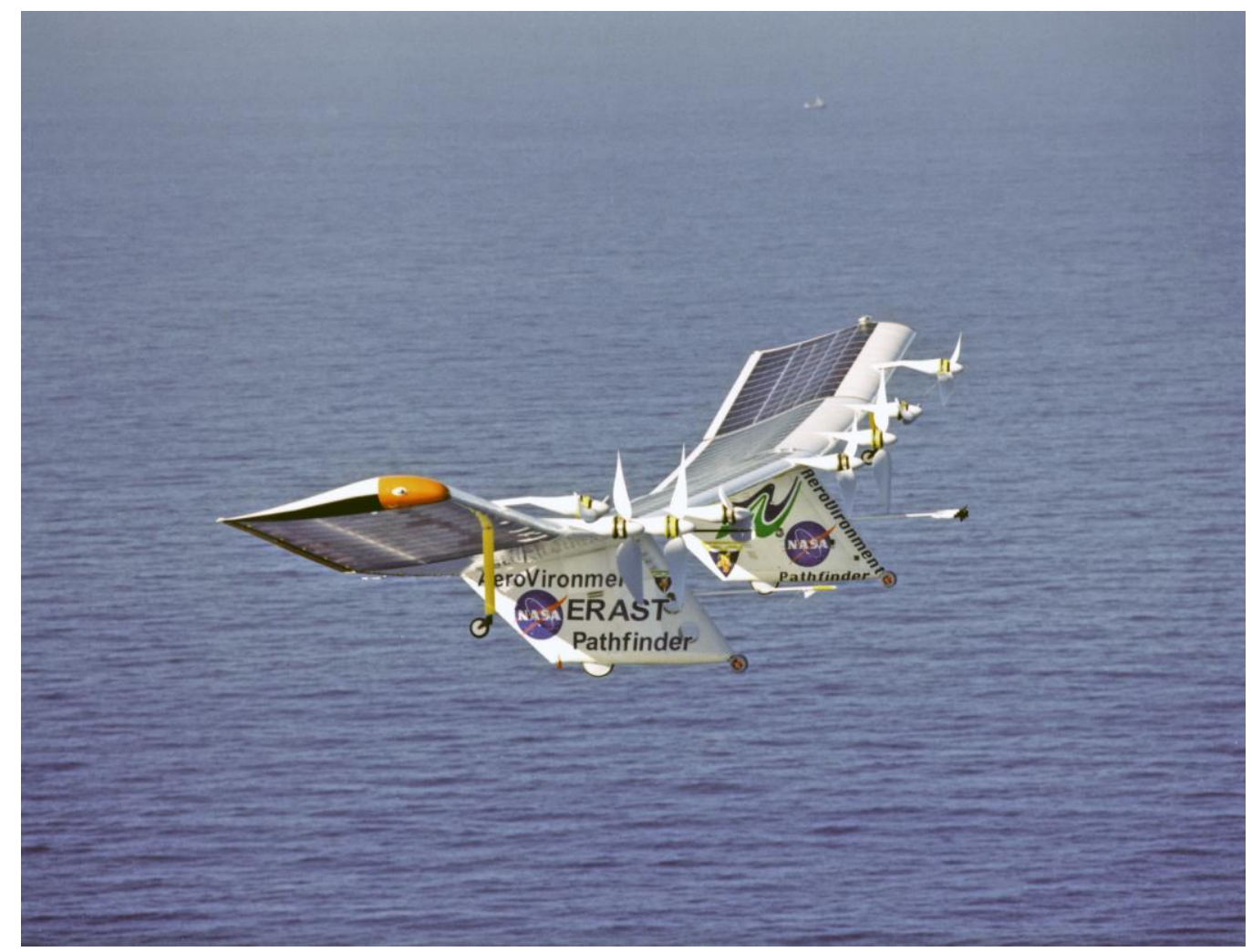

A more recent HALE UAS platform development is the Northrup-Grumman Global Hawk (Figure 11). NASA and NOAA have collaborated to utilize the Global Hawk UAS to support a number of scientific remote sensing campaigns since 2008. The Global Hawk has an operating altitude of 19,800 $\mathrm{m}$ and a flight endurance of over $30 \mathrm{~h}$. The NASA Global Hawk cruises at $550 \mathrm{~km} / \mathrm{h}$ and carries a payload of $750 \mathrm{~kg}$ for a range of over 17,000 km. The platform has compartments that can house over 10 different instruments, supporting multiple science instrumentation measurement capabilities. 
Figure 11. The NASA/NOAA Global Hawk HALE UAS. Image courtesy NASA.

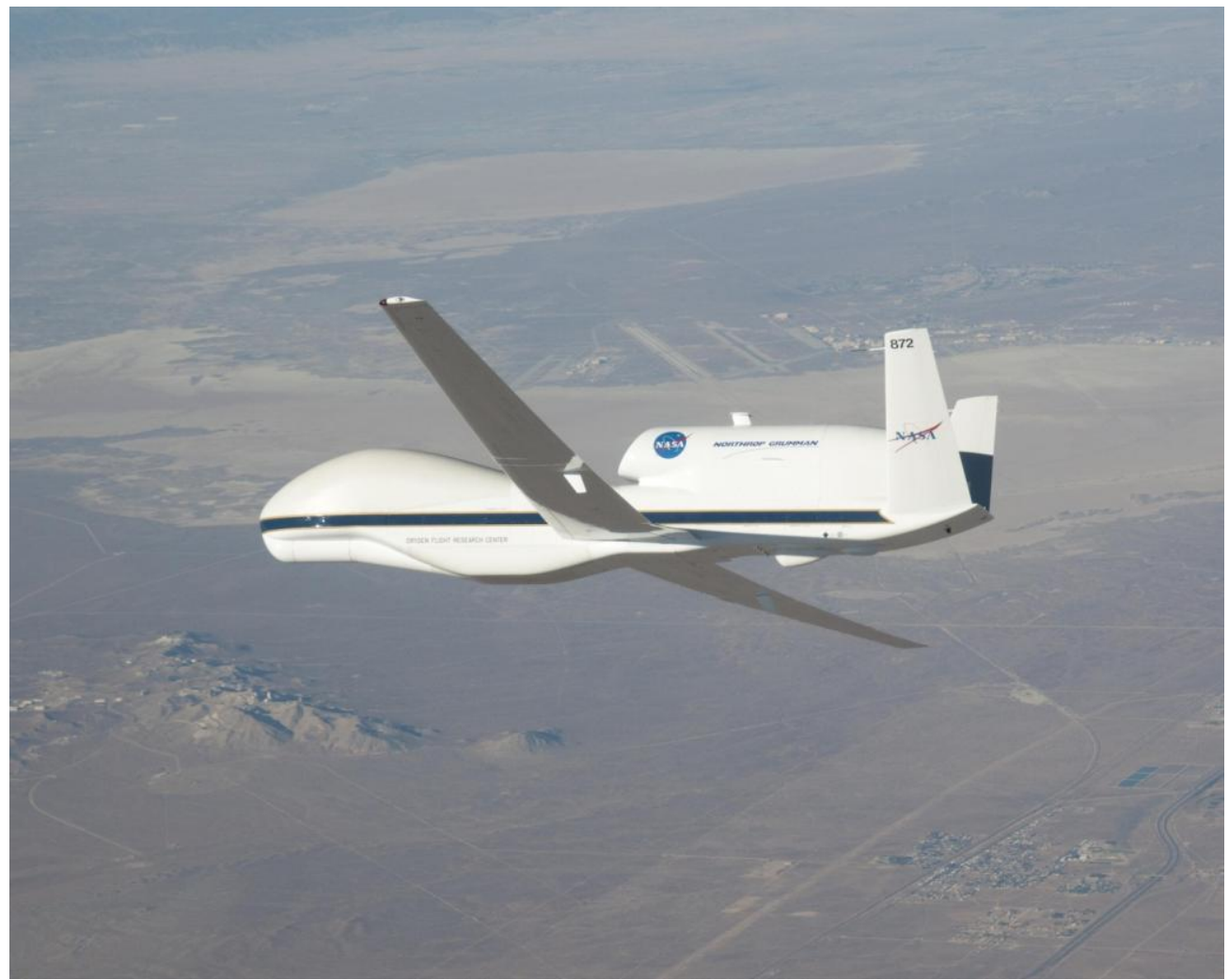

The 2010 Global Hawk Pacific Mission (GloPac) campaign was the first NASA Earth Science campaign to be conducted on the aircraft. Ten instruments were installed in the HALE UAS to support measurements of trace gases, aerosols and dynamics of the upper troposphere and lower stratosphere. The instrumentation also supported validation efforts of the instruments aboard the NASA Aura and CALIPSO earth-monitoring satellite.

The Genesis and Rapid Intensification Process (GRIP) hurricane surveillance mission's purpose was to better understand how tropical storms form and develop into major hurricanes. This campaign was conducted to capitalize on a number of ground networks, airborne science platforms, and space-based assets. The GRIP deployment was 15 August-30 September 2010 with the Global Hawk operating from NASA Dryden Flight Research Facility, CA, USA, flying to the Atlantic to measure and track hurricane systems while other sampling aircraft (manned) flew shorter mission legs from Florida and Texas.

The 2011 Winter Storms and Pacific Atmospheric Rivers, or WISPAR campaigns, were a series of observations led by the National Oceanic and Atmospheric Administration (NOAA) during long-duration NASA Global Hawk flights over the Pacific Ocean that explored atmospheric rivers and Arctic weather and collected targeted observations designed to improve operational weather forecasts. The missions were run from February to March 2011. The airborne campaign focused on improving scientists' understanding of how atmospheric rivers form and behave and evaluating the operational use of unmanned, high-altitude aircraft for investigating these phenomena. The research was also designed to assist NOAA in conducting potential offshore monitoring of atmospheric rivers to aid in future weather predictions. 
Starting in summer 2012, the Hurricane and Severe Storm Sentinel (HS3) will be a five-year mission specifically targeted to investigate the processes that underlie hurricane formation and intensity change in the Atlantic Ocean basin. HS3 will utilize two Global Hawks, one with an instrument suite geared toward measurement of the environment and the other with instruments suited to inner-core structure and processes.

Missions planned for 2013 and 2014 include the Airborne Tropical Tropopause Experiment and will employ the NASA Global Hawk to study the stratospheric humidity, ozone concentrations, and water vapor climate to improve our assessment of changing climate and feedbacks. The missions are planned for operations in Guam and Darwin, Australia.

Extreme long-duration platforms, like the Qinetiq Zephyr (Figure 12), are built of carbon-fiber composites, with lithium sulfur batteries taking energy from the solar cells that compose the upper surface of the wing. These platforms will see more civilian utility in the near future, supporting regionalized, long-duration observations. The Zephyr already holds the UAS endurance record (set in July 2010) for its sustained flight of 336 h, 22 min (two weeks). Currently, the aircraft has a service ceiling of $\sim 21,000 \mathrm{~m}$ and a payload of $2.5 \mathrm{~kg}$. It is envisioned that the Zephyr will provide 3-month on-station capabilities.

Figure 12. The Qinetiq Zephyr HALE UAS. Image courtesy QuinetiQ Group, PLC, Farnborough, Hampshire, England.

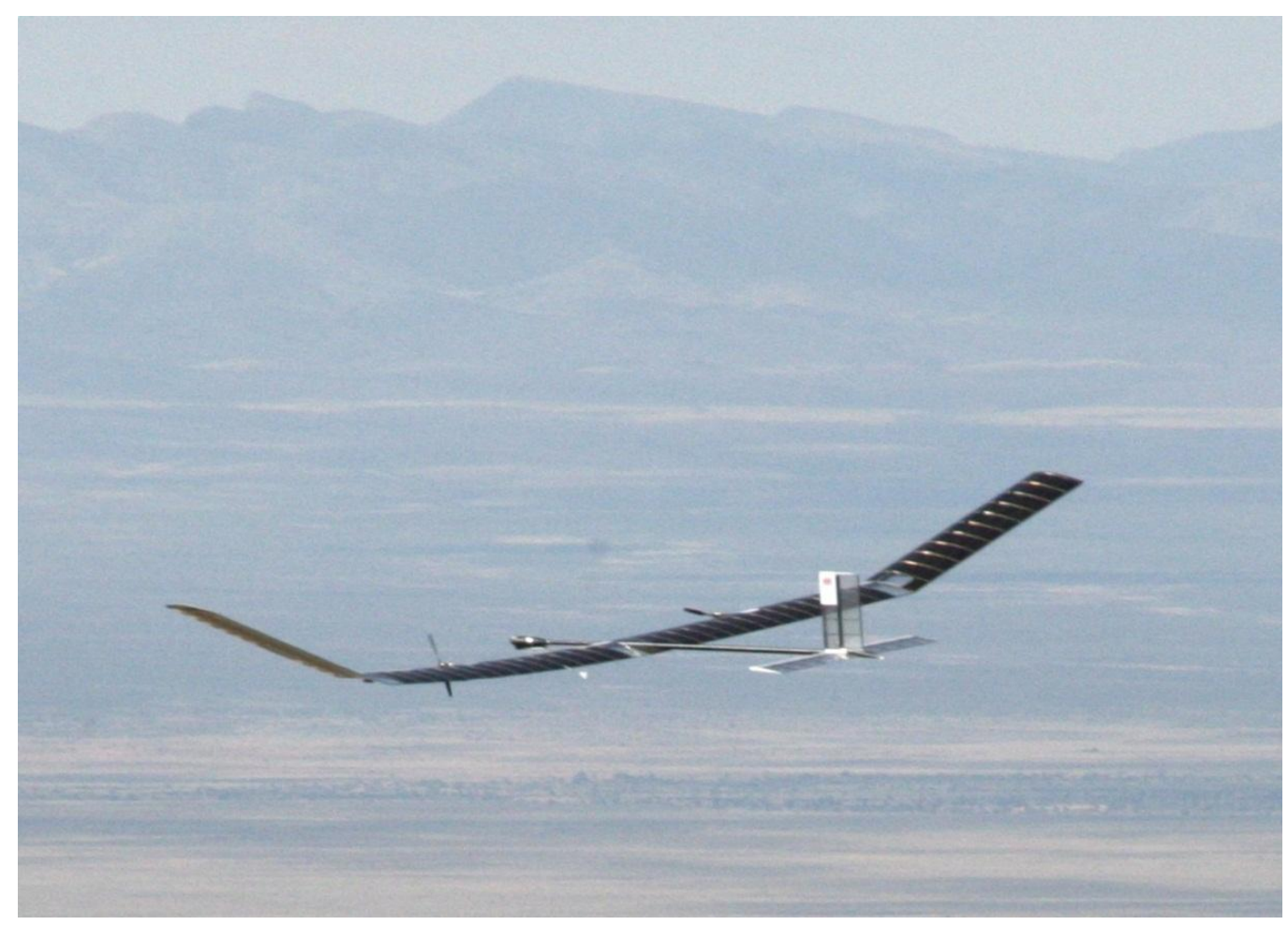

HALE UAS platforms are primarily valuable for strategic observation of large-scale (global/continental) phenomena where other platforms do not have the flight characteristics to support extensive mission operations. Platforms like the Global Hawk and the Zephyr (and other, similar platforms currently in development) will see increased use in atmospheric studies, and there are indications that HALE platforms in the next few years could provide near-continuous coverage of the 
Earth's surface through long-endurance flights lasting from one month to up to five years. These sub-orbital observations would provide a significant cost savings over satellite platforms, allowing a HALE UAS to be repeatedly returned to earth for sensor modifications/upgrades and the addition of new payloads. This is not feasible with current, costly orbital assets.

\subsection{Consideration of Payloads, Logistics Requirements}

The pace of technological development and rapid emergence of commercial providers of UAS and their services make estimations of platform and per-hour cost difficult, leaving potential users of UAS technology better served to consider their options based on sensor capabilities of available platforms. Many LASE systems are available with visible-spectrum cameras or, in some cases, near-infrared camera payloads. Often these systems, some of them based on RC model platforms, can be purchased outright for less than the price charged by a UAS services contractor for an individual job. However, numerous investigators have found the inadequacies of such systems which make them unsuitable for generating more than "snapshot" views of sites, recalling the pedigree of this class of UAS as situationalawareness tools for the military. When study plans call for spatial analysis of imagery (such as importation into GIS), the simultaneous collection of imagery with positional data is required in order to provide for image georeferencing. The latter capability is found increasingly among the smallest autopilot systems, but continues to require the collection of data from ground control points (GCPs). In order to eliminate GCP data collection, the UAV must add precise attitudinal data to imagery, allowing for direct image georeferencing [14,15]. In general, LALE UAS provide a direct image georeferencing capability, and combining this feature with small size (i.e., in LASE UAS) is difficult.

Payloads that deliver images in the visible and near-infrared spectral ranges tend to be among the lightest and are common to nearly all UAS platforms, due in part to considerable advancements in consumer-grade imaging products during the past decade. Thermal-infrared imaging is found less commonly aboard small UAS, with the exception of the AeroVironment Puma and Raven models whose low-resolution IR sensors are not linked to navigation data. Heavier still among electro-optical sensors are multispectral and LiDAR payloads, which weigh several $\mathrm{kg}$ and require power sources beyond the capabilities of small UAS to provide. Such payloads are more commonly found aboard MALE-class or larger UAS; there, high operational costs of the UAS and sensors can be balanced by long flight durations and large coverage areas. Exotic payloads such as atmospheric sampling or gas analysis systems and RADAR currently require the capabilities only large UAS can provide, and are typically deployed in operations funded among multiple publicly-funded agencies.

\section{Discussion}

\subsection{Regulations Governing UAS Use}

The majority of published studies regarding use of UAS for scientific research or other public-use missions do not discuss laws regarding use of unmanned aircraft in the airspace above the study site. This commonality conforms to conventions of scientific journals-some of which are beginning to require evidence of adherence to regulations by authors using UAS in their studies - but it belies the importance of considering regulations when planning an operation that may involve UAS. Most 
jurisdictions that regulate manned-aircraft flight in their airspace also restrict some aspect of unmanned aircraft use. Motivations behind these restrictions include safety of people on the ground and aloft as well as security against the misuse of UAS. These regulations evolve in response to emerging technology and potential accidents, but general concepts that underlie new rules tend to be stable despite changing political and technological landscapes.

In the United States, the FAA oversees both manned and unmanned aircraft operations, providing regulations and guidance on airspace restrictions, pilot requirements, and equipment and performance requirements. Since the FAA's main concern about UAS operations in the US National Airspace System (NAS) is safety, it is critical that UAS do not endanger current users of the NAS, including manned or other unmanned aircraft, nor compromise the safety of personnel and property on the ground. Therefore, the FAA has instituted rules restricting UAS operations in the NAS. In 2007, FAA clarified UAS regulations requiring that all UAS aircraft must apply for flight operations through a UAS Certificate of Authorization or Waiver (COA [16]). The FAA COA is an authorization issued by the FAA Air Traffic organization (ATO) to a public operator for a specific activity. After a complete application is submitted, FAA conducts a comprehensive operational and technical review. If necessary, provisions or limitations may be imposed as part of the approval to ensure the UAS can operate safely with other airspace users.

The COA process is available to public entities (including military, law enforcement, and other government agencies) who want to fly UAS in civil airspace. The FAA issues a COA generally based on three main restrictions. First, the COA authorizes an operator to defined airspace and includes special provisions unique to the proposed operation (such as requirement to only operate under Visual Flight Rules (VFR)). Most COAs are issued for a specific time period (up to one year, in most cases). Second, most COAs require coordination with the appropriate air traffic control facility and may require the UAS to have a transponder to operate in certain types of airspace. Third, due to the inability of UAS to comply with "see-and-avoid" rules, a visual observer or an accompanying chase aircraft must maintain visual contact with the UAS and serve as its "eyes" when operating outside restricted airspace [17].

A Special Airworthiness Certificate in the Experimental Category (SAC-EC) is an additional route available to obtain approval for UAS operations in the NAS. Its regulations stipulate that the aircraft cannot carry personnel or property for compensation or hire. The SAC-EC does allow operations for research and development, market survey and crew training, but effectively prohibits commercial UAS operations in the US.

UAS can operate within the guidelines of an active Restricted Area (RA), within active Warning Areas (WA) or within active prohibited areas, when authorized, such as a Military Operating Area (MOA), under specific guidance and direction by the holders of the RA/MOA. Both areas (RA/MOA) are generally under the control of government DoD operators (military bases, etc.), and are responsible for their own airspace and regulate the airspace of all aircraft that are in that space. If military operations or facilities are involved in UAS flights (such as a MOA), prior coordination with the appropriate DoD office is required [18].

Regulations concerning UAS operations vary widely throughout the world. European airspace regulations are similar to those in the US, but policies of individual member countries differ considerably in their requirements. Despite their intent on providing for safety of their respective national airspace 
systems, US and European UAS regulations have been blamed for discouraging the development of a commercial UAS market suitable to support scientific research at the scale of small agencies.

\subsection{Current US Regulations}

The new FAA reauthorization bill that was signed into law the week of 14 February 2012 by President Barack Obama creates a fast track for the integration of civil unmanned aircraft systems into the national airspace. The legislation states that the FAA and the UAS industry must work together to develop a "comprehensive plan" by mid-November (2012) that will safely achieve the full integration of UAS by 30 September 2015. Deadlines for certain smaller systems are set even sooner. For example, first responders will be allowed to fly small UAS weighing $2 \mathrm{~kg}$ or less within 90 days. Within six months, the FAA must designate six test ranges where the UAS can fly to develop their sense-and-avoid capabilities.

Recent FAA draft proposed UAS operations guidelines identify an upper limit of $25 \mathrm{~kg}$ to define small UAS (sUAS) platforms. The FAA is currently developing strategies for implementation of this platform category into operational use, which could lead to final rules on civilian and commercial sUAS operations in the US by mid-2013. The FAA's sUAS Aviation Rulemaking Committee (ARC) has recommended dividing unmanned aircraft into operating groups ranging in maximum takeoff weight from $2 \mathrm{~kg}$ to $25 \mathrm{~kg}$. The committee recommended that the largest aircraft be restricted to "extreme remote" class G airspace [18,19].

Within one year, small UAS under 55 pounds will be allowed to fly in the Arctic regions of the US, $24 \mathrm{~h}$ a day, at an altitude of at least 2,000 feet. By mid-2014, small UAS that weigh less than 55 pounds will be allowed to fly in the NAS. The legislation says that all UAS must have a "sense and avoid capability", and standards will be set for the licensing of operators. The FAA also will be required to study the causes of accidents involving UAS [20].

Potential users should be aware of additional regulations that may affect the acquisition or transportation of UAS components. In the United States, the Department of State has responsibility for the control of the permanent and temporary export and temporary import of defense articles and services pursuant to the Arms Export Control Act ("AECA") and Presidential Executive Order 11958. Among other functions the AECA provides for enforcement of International Traffic in Arms Regulations ("ITAR"). ITAR regulations do preclude export of certain UAS components that can be deemed as under ITAR control, such as some GPS units, and inertial navigation systems for UAS. A UAS investigator should ensure that ITAR requirements are met when exporting or using UAS equipment in foreign locations [21].

\section{Conclusion}

The past decade's proliferation of UAS platforms and sensors provides unprecedented choices: where authorized, users may choose based on capability and, to an increasing degree, budgetary constraints. The continued trend of increasingly miniaturized components promises an era of tailored systems for on-demand remote sensing at extraordinary levels of sensor precision and navigational accuracy. The latter capability in particular will lead to the ability of researchers to remotely establish study sites at small spatial scales for fine-scale projects that can be repeatedly sampled without 
resorting to ground-control points, frequently obviating the need for site visits. While costs can be difficult to assess per mission or per flight hour due to varying requirements for personnel, sensors, and logistical support, improved reliability and technological miniaturization may be expected to reduce acquisition or operation costs.

The capabilities found in UAS offer to revolutionize natural-resources management, remote sensing, and numerous other fields to the same degree as the advent of GIS two decades ago. The utility of UAS in fire mapping applications, for example, has been clearly shown in a number of demonstrations on aircraft of varying size and capability. Based on recent demonstration missions, the US Forest Service envisions using LASE (Low altitude, short endurance) and MALE (Medium altitude, long endurance) UAS for fire detection and active fire monitoring missions. VTOL aircraft are particularly appealing in wildfire and disaster response situations where access to improved surface runways are seldom guaranteed. Beyond fire and disaster response, LASE and MALE UAS aircraft will provide a host of cost-competitive applications in resource mapping and monitoring applications. Envisioned applications include:

- Forest health monitoring: This application requires advanced electro-optical (E/O) sensor payloads, such as near-infrared and (in some cases) hyperspectral. Due to large areas of coverage required, MALE UAS are likely to be favored in the near term.

- Forest inventory: Coarse-scale inventory requiring lightweight E/O sensors may allow the use of LASE UAS, which would confer the additional advantage of operation away from runways.

- Wildlife surveys: Terrestrial flights for large-animal surveys have been conducted using LASE UAS, while MALE aircraft may be preferred for marine surveys due to requirements for extended operations.

- Avalanche patrols: Depending on local facilities and preferred operations styles, this application may utilize either MAVs carried by rescue personnel, or LASE or MALE UAS operated from larger or fixed stations.

- Air quality monitoring: Sampling payloads may require the additional lift capacity of larger UAS, but generally the geographic scope of the mission profile will determine whether short-duration flights by VTOL or the greater coverage and duration offered by LASE or MALE UAS are preferred.

- Plume tracking: For monitoring of water pollution, repeated flights from local platforms may be accomplished by VTOL UAS. However, extensive surveys such as those required to track oil spills may make MALE UAS preferable. Payload requirements, which will impact platform choice, will be driven by specific pollutant types.

- Groundwater discharge monitoring: Because these surveys are likely to take place over areas with easily-identified ground-control points (GCPs), the high costs associated with high-precision georeferencing payloads may not be necessary for UAS use by agencies charged with these missions. In the case of local-scale missions of this profile, LASE UAS equipped with visible-spectrum or IR payloads (for nocturnal surveys) may be used.

- Mine surveys: Operation inside small, confined areas without GPS coverage make VTOL and MAV or NAV UAS a likely choice for enclosed mines, while larger LASE or VTOL with exotic payloads (e.g., LIDAR, RADAR) can be envisaged to improve surveys and operations in open-pit mines. 
- Precision agriculture: Monitoring of crop health and precision application of chemicals require large payloads such as pesticide/herbicide applicators and advanced E/O sensors, as well as precise navigational and maneuvering capability. Relatively small areas of operation combine to yield a preference for larger VTOL UAS in these applications.

The HALE UAS remain at the upper end of the cost scale and will be available for select applications of global scale; climate, ocean and ice monitoring. These aircraft tend to be considered in situations where long duration and/or long distance requirements are essential to the success of the mission and trump concerns of operational cost.

Once airspace guidelines and access issues are resolved (by the FAA in the US, for example), additional thought and evaluation will be required to locate the optimum compromise of cost versus capability for many of these unique resource applications. Continuing advances in the miniaturization of remote sensing and positioning hardware, with an eye toward their use on UAS, is placing increasingly powerful monitoring and mapping equipment on ever smaller UAS platforms.

As UAS operation for peacetime uses becomes routine, we predict the evolution of multiple avenues of access to UAS for potential users. Government agencies or universities with budgets and facilities sufficient to acquire or develop and maintain UAS of their own, likely will remain among the largest users of UAS, while smaller agencies and non-governmental organizations with relationships to these groups may benefit from contributions of UAS capabilities by their larger partners. Additional availability of UAS through the acquisition of military surplus by approved users (such as government agencies) may provide some benefits through greater familiarity with UAS use and operation within these organizations, although the scientific benefits of surplus UAS in the face of such rapidly developing technology are questionable. Commercial UAS manufacturers will increasingly tailor their products to the needs of civilian clients as wartime military outlays for UAS stabilize and peacetime demand increases with regulatory clarification. Additionally, a service sector will evolve to offer UAS services such as leased systems, on-demand flights, or consultation for choosing appropriate platforms or analyzing UAS-generated data. While UAS manufacturing offers significant barriers to entry and competition from established companies, the affiliated-service sector likely will see dramatic growth in the coming decade.

The potential user of UAS technology will need to carefully consider their data gathering requirements and thus, the sensors needed to carry out their mission. Sensor size, weight and power draw coupled with flight duration requirements will largely determine the minimum aircraft size acceptable for the mission. Choosing unmanned versus manned aircraft is a decision that must also be made with care. Under current cost per hour pricing, manned aircraft often offer the cheaper and more efficient alternative; however, cost is not always the only consideration in fire and disaster response. Pilot and crew safety must also be considered along with human flight limitations.

UAS continue to undergo rapid technological progress, and regulatory bodies struggle to cope with this rapid evolution while balancing the economic, information, and safety needs of their constituents. The articles presented in this Special Issue showcase several of the most advanced studies and organizations utilizing UAS in the civilian sector to date. Readers whose needs may be met with UAS technology in the future should consider collaborations or consultations with these or other established UAS groups to maintain awareness of new technological advances. Industry associations such as the 
Association for Unmanned Vehicle Systems International (AUVSI, http://www.auvsi.com) or regulatory bodies such as the FAA's Unmanned Systems Program Office (http://www.faa.gov/uas) provide updates to enacted or pending regulations, and should be contacted by those wishing to explore UAS for their own studies.

\section{Acknowledgements}

The authors wish to acknowledge many of the early adaptors and influential UAS innovators who have contributed to the history as well as the improved understanding of UAS capabilities and operations in support of remote sensing and earth systems understanding. In particular, we would like to thank Ardyth Williams (FAA), Doug Davis (FAA-retired), Franklin Percival (USGS), Cheryl Yuhas (NASA), Andy Roberts (NASA-retired), Bruce Tagg (NASA), Brent Cobleigh (NASA), Steve Wegener (NASA-retired), Susan Schoenung (Longitude 122 West), Jenny Baer-Reidhart (NASA-retired), and Jeff Bauer (NASA). Other acknowledged innovators/practitioners include Mike Hutt (USGS), Kathe Rich (U. of Alaska-Fairbanks) and Greg Walker (U. of Alaska-Fairbanks). Any use of trade, product, or firm names is for descriptive purposes only and does not imply endorsement by the US Government.

\section{References}

1. Watts, A.C.; Kobziar, L.N.; Percival, H.F. Unmanned Aircraft Systems for Wildland Fire Monitoring and Research. In Proceedings of the 24th Tall Timbers Fire Ecology Conference: The Future of Fire: Public Awareness, Health, and Safety, Tallahassee, FL, USA, 11-15 January 2009; pp. 86-90.

2. Haydon, F.S. Aeronautics in the Union and Confederate Armies, With a Survey of Military Aeronautics Prior to 1861. In Military Ballooning During the Early Civil War; Johns Hopkins University Press: Baltimore, MD, USA, 2000; Volume 1.

3. Bowen, D. Encyclopedia of War Machines: An Historical Survey of the World's Great Weapons; Peerage Books: London, UK, 1977.

4. Hannavy, J., Ed. Encyclopedia of Nineteenth-Century Photography; Routledge, Taylor \& Francis Group: 2007; Volume 1, pp. 14-15.

5. Nyquist, J.E. Unmanned aerial vehicles that even geoscience departments can afford. Geotimes 1997, 42, 20-23.

6. Quilter, M.C.; Anderson, V.J. A proposed method for determining shrub utilization using LA/LS imagery. J. Range Manage. 2001, 54, 378-381.

7. Polski, P. DHS View of Unmanned Aerial Vehicle Needs. In Proceedings of AIAA 3rd Unmanned Unlimited Technical Conference, Chical, IL, USA, 20-23 September 2004.

8. Kaestner, R.; Thrun, S.; Montemerlo, M.; Whalley, M. A Non-Rigid Approach to Scan Alignment and Change Detection Using Range Sensor Data. In Field and Service Robotics: Results of the 5th International Conference STAR 25; Cooke, P.I., Sukkarieh, S., Eds.; Springer-Verlaag: Berlin, Germany, 2006; pp. 179-194.

9. Watts, A.C.; Perry, J.H.; Smith, S.E.; Burgess, M.A.; Wilkinson, B.E.; Szantoi, Z.; Ifju, P.G.; Percival, H.F. Small unmanned aircraft systems for low-altitude aerial surveys. J. Wildl. Manage. 2010, 7, 1614-1619. 
10. Merlin, P. Ikhana Unmanned Aircraft System: Western States Fire Missions. In NASA Monographs in Aerospace History \#44 SP-2009-4544; NASA: Washington, DC, USA, 2009; pp. 1-70.

11. Ambrosia, V.G.; Wegener, S.; Zajkowski, T.; Sullivan, D.V.; Buechel, S.; Enomoto, F.; Hinkley, E.A.; Lobitz, B.; Schoenung, S. The Ikhana UAS western states fire imaging missions: From concept to reality (2006-2010). Geocarto Int. 2011, 26, 85-101.

12. Ambrosia, V.G.; Wegener, S.S.; Sullivan, D.V.; Buechel, S.W.; Dunagan, S.E.; Brass, J.A.; Stoneburner, J.; Schoenung, S.M. Demonstrating UAV-acquired real-time thermal data over fires. Photogramm. Eng. Remote Sensing 2003, 69, 391-402.

13. Blakeslee, R.J.; Croskey, C.L.; Desch, M.D.; Farrell, W.M.; Goldberg, R.A.; Houser, J.G.; Kim, H.S.; Mach, D.M.; Mitchell, J.D.; Stoneburner, J.C. The Altus Cumulus Electrification Study (ACES): A UAV-Based Science Demonstration. In Proceedings of International Conference on Atmospheric Electricity, Versailles, France, 9-13 June 2003; p. 1.

14. Perry, J.H.; Mohamed, A.; El-Rahman, A.H.; Bowman, W.S.; Kaddoura, Y.O.; Watts, A.C. Precision Directly Georeferenced Unmanned Aerial Remote Sensing System: Performance Evaluation. In Proceedings of the Institute of Navigation National Technical Meeting, San Diego, CA, USA, 28-30 January 2008; pp. 680-688.

15. Wilkinson, B.E.; Dewitt, B.A.; Watts, A.C.; Mohamed, A.H.; Burgess, M.A. A new approach for passpoint generation from aerial video imagery. Photogramm. Eng. Remote Sensing 2009, 75, 1415-1424.

16. Federal Aviation Administration. Unmanned Aircraft Operations in the National Airspace System; Federal Register: Washington, DC, USA, 2007; Volume 72, pp. 6689-6690.

17. Federal Aviation Administration. Factsheet: Unmanned Aircraft Systems; Available online: http://www.faa.gov/about/initiatives/uas/ (accessed on 15 February 2012).

18. Federal Aviation Administration. Unmanned Aircraft Operations in the National Airspace System (NAS); Federal Aviation Administration Air Traffic Organization Policy Notice N JO 7210.766; US Dept. of Transportation: Washington, DC, USA, 2011; pp. 1-12.

19. Carey, B. Small UAS rule will begin phased entry of unmanned aircraft. Aviation International News Online 4 October 2011. Available online: http://www.ainonline.com/?q=aviation-news/ aviation-international-news/2011-10-04/small-uas-rule-will-begin-phased-entry-unmanned-aircraft (accessed on 23 October 2011).

20. Grady, M. Coming soon: Era of UAS? AVflash News 15 February 2012. Available online: http://www.avweb.com/avwebflash/news/ComingSoonEraOfUAS_206186-1.html (accessed on 15 February 2012).

21. Department of State. The International Traffic in Arms Regulations (ITAR); US Department of State, Directorate of Defense Trade Controls: Washington, DC, USA, Available online: http://www.pmddtc.state.gov/regulations_laws/itar.html (accessed on 15 February 2012).

(C) 2012 by the authors; licensee MDPI, Basel, Switzerland. This article is an open access article distributed under the terms and conditions of the Creative Commons Attribution license (http://creativecommons.org/licenses/by/3.0/). 